\title{
On the Innovative Practice Path of College Students' Archives Work
}

\author{
Fan Yang \\ Sichuan University of Arts and Science, Dazhou, China \\ Email: yangfan04404@163.com
}

How to cite this paper: Yang, F. (2020). On the Innovative Practice Path of College Students' Archives Work. Open Journal of Social Sciences, 8, 320-326.

https://doi.org/10.4236/jss.2020.812026

Received: November 27, 2020

Accepted: December 21, 2020

Published: December 24, 2020

Copyright (c) 2020 by author(s) and Scientific Research Publishing Inc. This work is licensed under the Creative Commons Attribution International License (CC BY 4.0).

http://creativecommons.org/licenses/by/4.0/

\begin{abstract}
The archives can be divided into three stages according to the filing time and the student files. This paper summarizes and analyzes all kinds of problems in the three stages, turns the difficulties and pain points in the work into innovation breakthrough points, puts forward corresponding solutions or measures, and constantly considers and innovates in the work practice, increases the filing range of student archives, and explores a feasible way of innovative practice of college student archives work.
\end{abstract}

\section{Keywords}

Student Archives Work, Filing Range, Innovative Practice

\section{Introduction}

In the outline of the 13th Five-Year Plan for the Development of National Archives, the state archives administration puts forward the requirements of "accelerating the improvement of the archives management system and enhancing the archives governance ability". So how to understand the meaning of archives governance? Liu Dongbin analyzed the concept of archives governance and archives management, as well as archives governance and archives administration. He pointed out that archives governance is the new stage of the development of archives administration. The core of archives governance is the rule of law. The new of archives governance is the legalization of archives governance, that is, the legalization of archives administration, in short, the rule of law File (Liu, 2019). With the promulgation of the new archives law, which was revised and passed on June 20,2020, there will be laws to follow in managing archives according to law and the construction of archives legal system. In terms of regulations, there should be rules for the work of students in colleges and universities. The significance of the work of College Students' archives lies in that they are related to 
their employment, household registration and the identification of cadres' identity after graduation. Colleges and universities take students as the main body, which is closely related to each student, so the work of College Students' archives must be more refined and standardized.

The work of College Students' archives mainly includes the filing of Freshmen's files, the filing of filing materials and the transfer of graduates' archives. On the basis of doing a good job in file management, university archives should strengthen the construction of archives culture, which is the core level of university archives work (Tu, 2019). Among them, the collection of students' archives is also a rich file resource, which builds the foundation for the cultural construction of colleges and universities. The work of transferring graduates' archives is related to the future of every student. Therefore, it is of great significance to do a good job in the work of students' archives. However, there are still some problems in the actual work, which are worth discussing.

\section{Problems Existing in the Establishment of College Students' Archives}

According to our research in Universities in Sichuan Province, some colleges and universities receive freshmen files uniformly by the enrollment and employment department, some colleges and universities uniformly receive them by the student department, some colleges and universities uniformly receive them by the academic affairs office, some colleges and universities are separately collected by the secondary colleges, and some colleges and universities are received by relevant departments and Archives. No matter which department receives the students' files first, they will be put into the archives, which will lead to the problem that the transfer procedure of Freshmen's archives may not be standardized and reasonable. First, due to a large number of students, the files received by the enrollment and employment department or the student office or the academic affairs office may lead to the problem that the files are stacked disorderly and cannot be handed over to the archives in time according to the class number of the college. During this period, there may be risks such as wrong classification of college classes, loss and damage of student files. Second, the problem that secondary colleges may encounter in receiving archives is that teachers in secondary colleges generally ask student cadres to help them receive and sort out the files. They do not pay enough attention to the files, and there may be the problem of unsealing the files. Finally, there are students with the same name and surname when filing the freshmen's files, which leads to the problem of putting up the files with different names.

\section{Problems Existing in the Filing of College Students' Archives}

After the completion of the freshmen files, they should be divided into different schools, with the class as the unit, sorted by the student number from small to large, and then stored in the warehouse. Before warehousing, it is necessary to 
sort out and check whether each student's file materials are complete and complete, and there is a problem that students' files are lack of materials every year. For example, some students' files are lack of college entrance examination files, some are lack of high school students' status or League organization files. Among them, according to the source of students, some places send the files together with the college entrance examination files, some places send them directly to the Youth League Committee of the school, and some let the students take them with them, which leads to many problems in the collection of League organization files. In addition, according to the filing scope of student files stipulated in the "measures for the management of University Archives", each student will have the corresponding materials to be put into the file bag during the school period. The materials included in the scope of filing are produced by different departments. There are many problems in filing materials, such as whether to fill in the standard, whether to affix official seal, whether to paste photos and whether the list of handover forms is consistent with the quantity of physical materials.

\section{Problems in the Transfer of College Students' Archives}

The transfer of College Students' archives is the "last kilometer" of College Students' archives work. Therefore, every link should be extra careful. The problems are summarized as follows:

First, the filing materials of individual departments before the transfer of archives did not correspond to the transfer list one by one. Some of the materials were not sorted according to the order of the list of graduates dispatched by the Department of enrollment and employment. Some materials were surplus, some were lack of materials, and they were handed over to the archives without checking and verifying. In addition, some departments did not hand over the electronic version of the handover list together.

Second, before the file is transferred, the address is not detailed, the recipient and contact number are missing, and even the address is wrong. It may be that the address provided by the students is wrong, or the secondary college may make an error in registering the dispatch address to the enrollment and employment office. Once the files are transferred out, the files are either returned; or we need to issue a file transfer letter or contact the other party's units to recover the files and then re-transmit them. There is also the problem that the receiving unit does not have the right to manage the files filled in by individual graduates. Once the files have been transferred, the other party has received the files, resulting in the files in the hands of individuals. After a certain period of time, they become black files that have no units to receive.

Third, during the transfer of archives, there are problems of wrong loading and missing loading of archival materials. For example, the file materials of the later student are wrongly loaded into the file bag of the former student, resulting in the situation that the latter several students load the wrong files continuously. 
After the files are transferred out, the number of students involved in solving the error is relatively large, so it is more troublesome to deal with this problem. Another example is that after a student's file is transferred out, it is finally found that there are still materials not put into the student's file bag. Then, it is necessary to contact the file receiving unit, and then forward it through the way of supplementary mail. However, there is no way to do it. Generally, files are not allowed to be transferred in batches.

Fourth, during the transfer of archives, there are more archival materials. For example, two internship assessment books and two graduate registration forms of students were put into the file bag and transferred out, resulting in the lack of this part of archives in secondary colleges.

Fifthly, due to manual delivery and weather and other reasons, the special bag of Postal EMS is damaged during the delivery process, resulting in the archives being soaked by rain, which may cause damage or even damage to the archives.

Sixth, the students did not report in time to confirm whether their files were transferred to the reporting unit. College students file transfer now generally use EMS express mail, can only provide three months of express details query time, more than this time period cannot query the detailed record of the express process.

\section{Solutions to the Problems Encountered in the Work of College Students' Archives}

In view of the problems encountered in the three stages of College Students' archives work, this paper summarizes the following corresponding solutions or measures through working practice:

First, in view of the problems existing in the filing work of college students, it is more reasonable to adopt the way of receiving students' files separately by secondary colleges. Because the secondary college is the most familiar with the situation of the students in the college, contact with students is the most convenient and fastest, timely communication and problem-solving can also be achieved. The specific path is: the secondary college adopts the front-end control. Before the freshmen register, the QQ group and WeChat group of the freshmen are established to establish a good communication channel with the freshmen. Then, each freshman can send their personal files to the school to fill in the mailing address accurately to each major of the secondary college, so that when the secondary college receives the files, it will be directly separated according to the college specialty classification To avoid mixing the files of different secondary colleges together, we can further separate the files of students of different majors, and solve the problem of students with the same name and surname in different colleges and different majors. In addition, the archives should seize the key nodes to issue notices, contact and communicate with the secondary colleges in time, confirm the teachers who receive the freshmen's files, and emphasize the matters needing attention when receiving the freshmen's 
files, especially when asking the student cadres to help them receive and sort out the files.

Second, in view of the problems existing in the filing work of College Students' archives, after the completion of Freshmen's file sorting and review, if there is a lack of college entrance examination files, League organization files and high school student status materials, immediately inform the students themselves, and send the corresponding file materials to the original college entrance examination enrollment office or high school. In view of the special problems of the League organization files, through practice, it is proposed to use the school intelligent league construction management system, and the League organization files of students during the school period are collected and managed by the school Youth League Committee. On the one hand, the archives will hand over the files containing the League organization files to the Youth League Committee of the University. On the other hand, the League organization files brought by students themselves will be handed over to the Youth League Committee of the University. In addition, the Youth League organization files directly sent to the College Youth League Committee will be complete. After graduation, it will be handed over to the archives by the Youth League Committee of the University. Secondly, for the materials that can't be filled in with official seal, they should be filled out in red ink, and the materials that can't be signed and filed in red should be filled in by the person who can't sign and file in person; for the materials that can't be written in blue, they should be filed in black Students' physical examination form, student registration form, three good students, excellent student cadres, outstanding graduates, scholarship application form and other materials should be pasted with photos; finally, each material should be compared with the handover form, and the name and quantity of each material should be checked one by one to ensure that the file name and quantity corresponding to each person on the handover form are consistent with the physical materials. After verification, both parties shall sign for confirmation.

Thirdly, in view of the problems existing in the transfer of College Students' archives, corresponding measures should be taken in accordance with the three links before, during and after the transfer. Before the transfer of archives, the filing materials of each department shall be sorted into one set according to each person, and then sorted according to the order of the list of graduates dispatched determined by the enrollment and employment department, and then handed over to the archives after one by one verification. Both parties shall sign on the transfer list for confirmation, and the electronic version shall be handed over together for reference. The forwarding address should be accurate to the house number of the archives receiving unit, and there must be a contact person and contact number. What needs to be paid special attention to is that the enrollment department should check whether the receiving unit has file management authority for the files filled in by students one by one, and finally require each student to sign for confirmation. During the transfer of archives, in order to 
avoid the problems of wrong loading, missing loading and over loading of archival materials, the filing materials of each student's archives are required to be preliminarily checked and resealed after being verified to be correct. After communication with the postal group company, in order to solve the problems in the delivery process, the EMS student file special bag was redesigned, and a layer of wear-resistant and waterproof material was added inside. After the files are transferred out, the EMS express order number shall be uploaded as soon as possible. It is emphasized that the time limit for the EMS official website to query the detailed transmission records is 3 months, and the secondary college shall timely inform the graduates to inquire and confirm whether their files have been delivered to their employment units or institutions receiving and keeping their archives.

\section{Some Thoughts on the Innovative Practice of College Students' Archives Work}

The problems encountered in the work of College Students' archives, that is, the difficulties and pain points in the work, are the innovation breakthrough points of our work. The following are my thoughts on the innovative practice of College Students' archives work in practical work.

First, the methods and measures summed up in practice should be institutionalized to form rules and regulations or work processes. In the face of tedious student archives work, if we always rely on memory to carry out the work, it is inevitable that there will be deviations and empirical mistakes. Therefore, in the development of student archives related systems and processes, we should as far as possible refine the responsibilities of the corresponding staff. We have formulated the work flow of the archives, such as the work flow of freshmen filing, the key points and handover procedures for the examination and approval of student archives transferred by various departments (colleges), the centralized transfer workflow of student archives, and the sporadic transfer workflow of student archives, so as to provide institutional guarantee for the standardization of student archives work.

Second, in the practice of student archives work, we should take students as the foundation, and think about innovative working methods from the perspective of archives utilization. In recent years, we always encounter the situation that graduates return to school to inquire about the internship assessment book, graduate registration form and other files. These files are transferred out with the students' personal files, and the archives have not been kept. Therefore, we take the lead in the provincial colleges and universities to require students to fill in the enrollment registration form, internship assessment book and graduate registration form in duplicate. One copy is transmitted with the students' personal files, and the other is kept in the archives for future reference. On the one hand, the archives preserved in the archives can solve the problem that some graduates can't pass the political examination due to the loss or lack of files after 
they find a job or are admitted to civil servants or public institutions. On the other hand, these archives also enrich the archives resources of the university, especially those of outstanding alumni, and are the best resources for spreading the deeds of outstanding alumni in the future, at the same time, it can achieve the effect of strengthening the school culture. However, considering the contradiction between the limited capacity of the Archives storehouse and the huge quantity of these three materials, we started to digitize scan all the three materials from this year, only archiving the scanned electronic data, which not only solved the space capacity problem of the warehouse, but also met the needs of students for file searching.

Third, we should keep pace with the times, pay attention to the hot issues of the people's livelihood, connect with the work of student archives, broaden the working ideas, and make the work become warm. During the novel coronavirus pneumonia epidemic, we opened the mail appointment booking service, and solved the problem of archival query utilization through mail reply and SF express delivery, which met the needs of the utilization of teachers and students files. Recently, the online college entrance examination replacement incident, people's daily angrily criticized: lawlessness, trampling on fairness. We immediately started from the class of 2020 freshmen, with the freshmen's photos, examinee number bar code, enrollment major and other basic information into a volume and stored in the archives. The registration form of freshmen is an important original file for the examination of Freshmen's enrollment qualification and identity verification. In a sense, this work has safeguarded social equity, and naturally it is also meaningful work.

\section{Fund Project}

Sichuan University of Arts and Sciences BA culture research project: the protection strategy of BA culture from the perspective of Archival Science (2017bwh004y) phased achievements.

\section{Conflicts of Interest}

The author declares no conflicts of interest regarding the publication of this paper.

\section{References}

Liu, D. B. (2019). Concept Analysis of Archives Governance. Archives Management, 1, 47-49.

Tu, S. B, (2019). Research on Three Levels of University Archives Work. Zhejiang Archives, 1, 60-61. 